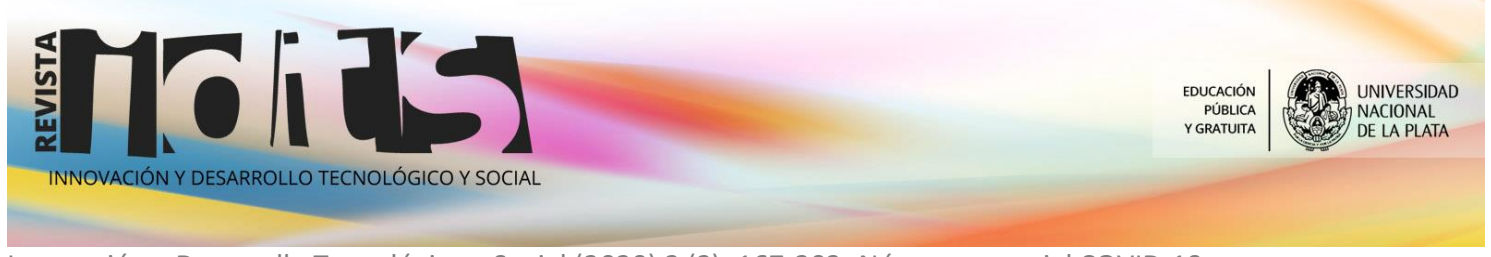

Innovación y Desarrollo Tecnológico y Social (2020) 2 (2): 167-203- Número especial COVID-19

\title{
Desarrollo de un esterilizador de aire UV-C para el control de la transmisión aérea del COVID-19
}

\author{
Manuel Macias "; César Luchetti 2, 3; Alicia Kitrilakis 4, 5; Sebastian Pelizza 6; Juan Laborde 7; \\ Miguel Ayala ${ }^{8}$; Martín Zubieta ${ }^{9}$
}

${ }^{1}$ Colaborador. Proyecto de Investigación Implantología Oral Fase VIII.UNLP; ${ }^{2}$ Integrante. Proyecto de Investigación Implantología Oral Fase VIII UNLP. Codirector. Carrera de Maestría en Implantología Oral. UNLP; ${ }^{3}$ Profesor Titular. Asignatura Prótesis A. Facultad de Odontología. UNLP; luchettic@folp.unlp.edu.ar; ${ }^{4}$ Director.Proyecto de Investigación Implantología Oral Fase VIII UNLP. Director. Carrera de Maestría en Implantología Oral. UNLP; ${ }^{5}$ Profesor Consulto. Facultad de Odontología. UNLP; ${ }^{6}$ Director. Instituto Spegazzini. Facultad de Ciencias Naturales. UNLP; 'Jefe del Área de Control Sanitario y Responsable de Área de Diagnóstico Molecular por PCR. Laboratorio de Animales de Experimentación. Facultad de Ciencias Veterinarias. UNLP; ${ }^{8}$ Director. Laboratorio de Animales de Experimentación. Facultad de Ciencias Veterinarias. UNLP; ${ }^{9}$ Coordinador del Área de Biología Molecular e Integrante del Consejo Asesor del Centro de Medicina Traslacional. Hospital El Cruce.

Resumen. En el contexto de la pandemia por COVID-19, y considerando que existe una transmisión área del virus, que la OMS tardó en reconocer, pero que hoy está comprobado, decidimos desarrollar un Esterilizador de Aire con una combinación específica de Filtros Especiales y el uso de Luz UV-C. Luego del desarrollo del esterilizador (Belerofonte I), se realizaron pruebas biológicas, con Virus, Bacterias, Hongos y Esporas, para ver su efectividad en esterilizar ambientes. Luego de los resultados contundentes obtenidos, y de las pruebas de flujo de aire realizadas en Ingeniería, el equipo se escaló a un tamaño más pequeño, logrando las mismas prestaciones (Belerofonte II). Con el segundo prototipo se repitieron las pruebas, mostrando la misma efectividad. Si bien el desarrollo se enmarca en la pandemia por COVID-19, sería de utilidad a largo plazo, dadas sus prestaciones, para evitar infecciones intrahospitalarias, y que podría ser aplicable a consultorios, transporte público, locales comerciales, entre otros.

Palabras clave: esterilizador de aire UV-C, SARS-COV-2, COVID-19 
Recibido: 26/09/2020 Aceptado: 30/09/2020

DOI: https://doi.org/10.24215/26838559e021

\title{
Development of a UV-C air sterilizer for the control of the air transmission of COVID-19
}

\begin{abstract}
In the context of the COVID-19 pandemic, and considering that there is an airborne transmission of the virus, which the WHO was slow to recognize, but is now proven, we decided to develop an Air Sterilizer with a specific combination of Special Filters and the use UV-C Light. After the development of the sterilizer (Belerofonte I), biological tests were carried out with Viruses, Bacteria, Fungi and Spores, to see its effectiveness in sterilizing environments. After the strong results obtained, and the air flow tests carried out in Engineering, the equipment was scaled to a smaller size, with the same performance (Belerofonte II). The tests were repeated with the second prototype, showing the same effectiveness. Although the development is a part to fight the COVID19 pandemic, it would be useful in the long term, given its benefits, to avoid intra-hospital infections, and it could be applicable to clinics, public transport, and commercial premises, among others.
\end{abstract}

Keywords: UV-C air sterilizer, SARS-COV-2, COVID-19

\section{Novedad u originalidad local en el conocimiento}

En el contexto de la pandemia por COVID-19, y considerando que existe una transmisión área del virus que la OMS tardó en reconocer, pero que hoy está comprobado, decidimos desarrollar un Esterilizador de Aire con una combinación específica de Filtros Especiales y el uso de Luz UV-C. La novedad del desarrollo consiste en utilizar tecnología conocida en una combinación nueva, que permita lograr los objetivos propuestos. 


\section{Grado de relevancia}

En el contexto de la pandemia por COVID-19, creemos que el desarrollo permitirá disminuir la carga viral, especialmente en áreas de gran concentración del mismo, tal como lo demuestran los estudios biológicos incluidos en el presente artículo. Desde nuestro grupo se espera que esta nueva tecnología se aplique a hospitales, centros de salud y consultorios en primera medida, así como también a la población en general.

\section{Grado de pertinencia:}

La pertinencia del desarrollo radica en los estudios biológicos realizados, que permiten observar la capacidad del equipo desarrollado en disminuir la carga viral y bacteriana de los ambientes en los que se utilizó.

\section{Grado de demanda}

El grado de demanda dependerá de la iniciativa de cada actor en el sector de salud, que tenga conciencia y conocimiento del producto desarrollado. La Universidad Nacional de La Plata ha brindado amplio apoyo al desarrollo propuesto, a partir de la Incubadora de Ideas y Proyectos Minerva, luego de numerosos estudios, a un producto sumamente innovador. 


\section{Desarrollo del producto}

A finales de diciembre del 2019 el médico oftalmólogo chino, Li Wenliang, intentó alertar a sus colegas médicos sobre un virus que creía que se parecía al virus del SARS. Los casos se registraron en el mercado de pescados y mariscos de Huanan, en Wuhan y los pacientes fueron puestos en cuarentena en su hospital ${ }^{1}$. Poco tiempo después, el número de casos creció exponencialmente, y se detectó que el virus tenía una tasa de contagio elevada y un índice de mortalidad de entre el 2 y el $8 \%$.

El 5 de enero del 2020 la OMS publica su primer parte sobre brotes epidémicos relativos al nuevo virus, una publicación técnica de referencia para la comunidad mundial de investigación y salud pública y los medios de comunicación. El parte contiene una evaluación del riesgo y una serie de recomendaciones, así como la información proporcionada por china a la OMS.

El 10 de enero del 2020 dicta recomendaciones a todos los países sobre cómo detectar casos.

El 13 de enero del 2020 se confirma oficialmente un caso de COVID-19 en Tailandia, el primero registrado fuera de China. El 22 de enero del 2020 la misión de la OMS a China emite una declaración en la que se afirma que se ha demostrado la transmisión entre seres humanos en Wuhan.

\footnotetext{
${ }^{1}$ BBC NEWS. February 7, 2020, Li Wenliang: Coronavirus death of Wuhan doctor sparks anger. https://www.bbc.com/news/world-asia-china-51409801
} 
El 30 de enero del 2020 el Director General de la OMS convoca al comité de emergencia, el cual llega a un consenso que el brote constituye una emergencia de salud pública de importancia internacional. El informe de situación a la fecha señala la existencia de un total de 7818 casos. El 11 de marzo del 2020 la OMS determina en su evaluación que el COVID-19 puede caracterizarse como una pandemia. ${ }^{2}$

El paquete de recomendaciones sobre las vías de contagio que tiene el COVID-19, hacen especial hincapié en el contagio por transmisión directa de persona a persona a través de gotículas y superficies contaminadas. ${ }^{3}$

El primer caso detectado en Argentina fue el 3 de marzo del 2020, se trataba de un hombre de 43 años que llegó a Buenos Aires procedente de Milán, Italia. Y el 18 de marzo el gobierno nacional decreta el aislamiento preventivo y obligatorio en toda la Argentina.

El 6 abril de 2020, la Universidad Nacional de La Plata a través de la Incubadora de Ideas y Proyectos Minerva convoca a todos los investigadores a tratar la problemática desatada por la emergencia sanitaria que se desencadenó por la propagación del coronavirus en el país, y buscar soluciones a través de proyectos presentados en dicha institución. ${ }^{4}$ Por lo tanto, se presentó el proyecto de

\footnotetext{
${ }^{2}$ COVID-19: cronología de la actuación de la OMS. 27 de abril de 2020. https://www.who.int/es/news-room/detail/27-04-2020-who-timeline---covid-19

${ }^{3}$ Report of the WHO-China Joint Mission on Coronavirus Disease 2019 (COVID-19). February 28, 2020 https://www.who.int/docs/default-source/coronaviruse/who-china-joint-mission-on-covid-19-finalreport.pdf

4 Incubadora de Proyectos Minerva. "Tu idea Suma". Convocatoria de ideas y proyectos ante la Pandemia de CORONAVIRUS (COVID-19) - 6 de abril de 2020 https://unlp.edu.ar/vinculacion tecnologica/tu-idea-suma-17693
} 
fabricación de un esterilizador de aire UV-C, el cual fue posteriormente seleccionado como estratégico por la UNLP ${ }^{5}$. En dicha convocatoria se plantea la necesidad de hacer especial hincapié en disminuir los contagios del COVID-19.

En su reporte sobre las vías de transmisión, la OMS descartó la vía de transmisión aérea, fundamentándose en que las partículas virales son de gran tamaño (80 a 150 Nm), pudiendo en todo caso trasladarse por vía aérea solo 2 metros. Esta afirmación realizada por la OMS fue resistida por muchas instituciones por falta de evidencia y de información proveniente desde China. Es así que se planteó que hubo un error de diagnóstico con respecto a las vías de transmisión del virus, ya que, dado el gran número de casos y el patrón inconexo entre cantidad de casos y vías de contagio, debía incorporarse la transmisión por vía aérea.

Expertos de todo el mundo advirtieron a la OMS que bajo ciertas circunstancias el COVID-19 se contagia por aire. Ante tal afirmación, la OMS fue muy cautelosa, ya que las pruebas eran indirectas. Sin embargo, agregó una actualización en el documento sobre formas de transmisión del virus ${ }^{6}$, incluyendo los aerosoles presentes en el ambiente, basado en estudios independientes (Morawska y Milton, 2020). De este modo se planteó la necesidad de tratar el aire, filtrarlo y esterilizarlo en forma segura y rápida para las personas.

\footnotetext{
5 Incubadora de Proyectos Minerva. "Tu idea Suma. COVID-19" Proyectos estratégicos seleccionados. https://unlp.edu.ar/coronavirus/tu-idea-uma-covid-19-proyectos-estrategicos-18286

${ }^{6}$ Organización Mundial de la Salud. Información Actualizada sobre el COVID-19. septiembre de 2020. https://www.who.int/es/emergencies/diseases/novel-coronavirus-2019
} 
Por lo expuesto anteriormente, planteamos que los mecanismos de contagio del COVID-19 implican necesariamente, no solo contacto directo, sino también dispersión de microgotas en el ambiente, permaneciendo en el mismo, y es por ello que en el presente estudio se procedió al desarrollo de un equipo para esterilizar el aire.

\section{Objetivo general:}

Disminuir la tasa de contagio del COVID-19 en espacios confinados y de alta carga viral mediante el uso del equipo de esterilización de aire UV-C (Belerofonte II).

\section{Objetivos específicos:}

1) Evaluar la eficacia de esterilización ambiental del equipo desarrollado.

2) Evaluar los tiempos específicos del uso de la luz UV-C, en la esterilización de cepas fúngicas y de esporas altamente resistentes cuando son expuestas de manera directa a la misma.

3) Comprobar la susceptibilidad de diversas cepas virales a la luz UV-C, a través del equipo desarrollado.

4) Establecer los coeficientes necesarios para descontaminar un ambiente de acuerdo a sus dimensiones.

5) Desarrollar un equipo que se factible de utilizar en presencia de pacientes y personal de la salud, sin riesgos para las personas, a diferencia del uso de la luz UVC tradicional. 
Innovación y Desarrollo Tecnológico y Social (2020) 2 (2): 167-203- Número especial COVID-19

\section{Materiales y métodos}

Se planteó y ejecutó la construcción de un prototipo (Belerofonte I). Este primer prototipo fue desarrollado analizando las condiciones que se pueden dar en una terapia intensiva. En términos generales, las terapias intensivas de los diversos hospitales del país oscilan entre 50 a $200 \mathrm{~m}^{3}$, con capacidades de entre 5 a 30 camas con su respectiva aparatología de apoyo vital. Los parámetros que se tuvieron en cuenta para el desarrollo del prototipo fueron que debía trabajar en presencia de una alta carga del virus SARS-CoV-2 en el ambiente, producto de una alta concentración de gotículas en el ambiente. Presencia de una alta carga de diversos microorganismos oportunistas propios de un ámbito hospitalario. Presencia de personal sanitario altamente expuesto al SARS-CoV-2. Con estos parámetros se desarrolló el prototipo, el cual debió tener el requisito de esterilizar como mínimo un volumen de aire de $50 \mathrm{~m}^{3} / \mathrm{h}$, que pueda trabajar de manera continua y cumplir con el requisito fundamental de no exponer a las personas a la radiación UV-C.

A diferencia de otras técnicas de esterilización basadas en radiación UV-C el equipo debió cumplir el requisito de poder ser utilizado en presencia de los pacientes y del personal de salud. Desde el punto de vista técnico el equipo consta de motores forzadores de aire, cámara de esterilización y filtros hidrorepelentes.

A partir de este desarrollo, se realizaron las primeras pruebas para demostrar su eficacia. Luego de los resultados satisfactorios obtenidos, se comenzó un trabajo en equipo con una empresa privada, quienes de manera conjunta con la Facultad de 
Ingeniería UIDET - Capa Límite y Fluido Dinámica Ambiental (LaCLyFA) de la UNLP, realizaron estudios para poder mejorar el equipo inicial, necesarios para poder calibrar correctamente los valores de caudales de flujos de aire, dando como resultado un segundo prototipo (Belerofonte II), con mejores prestaciones, la mitad del tamaño y más ergonómico que el prototipo inicial (Morawska et al, 2020) (Figuras 1 y 2). A partir de allí, se ampliaron las pruebas biológicas de laboratorio, las cuales fueron realizadas en la Facultad de Ciencias Naturales y Museo y en la Facultad de Ciencias Veterinarias de la UNLP.

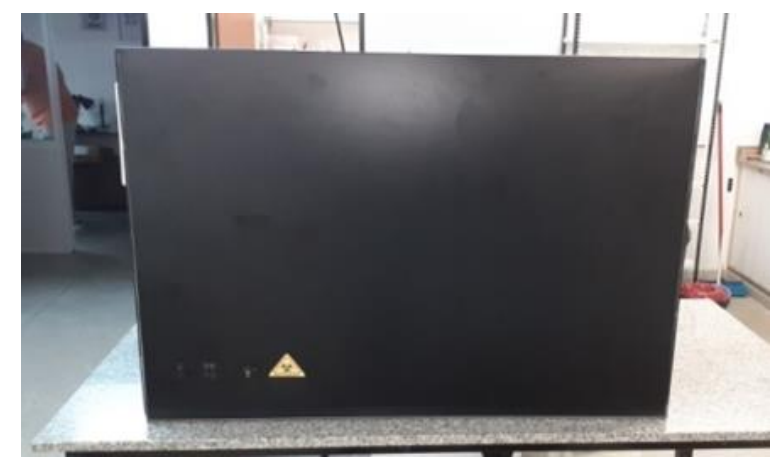

Figura 1. Vista lateral izquierda del prototipo "Belerofonte I", 1 metro de largo x $45 \mathrm{~cm}$ de ancho y $70 \mathrm{~cm}$ de altura.

Figure 1. Left side view of the "Bellerophon I" prototype, 1 meter long $x 45 \mathrm{~cm}$ wide and $70 \mathrm{~cm}$ high. 


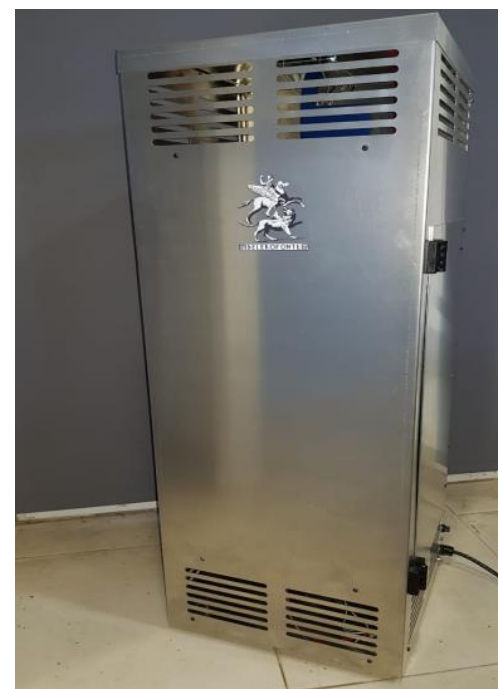

Figura 2. Vista frontal del prototipo "Belerofonte II". 1 metro de alto x $35 \mathrm{~cm}$ de ancho y $35 \mathrm{~cm}$ de profundidad.

Figure 2. Front view of the "Bellerophon II" prototype. 1 meter high $\times 35 \mathrm{~cm}$ wide and $35 \mathrm{~cm}$ deep.

\section{1) EVALUACION DE PRUEBAS DE ESTERILIZACION DE AMBIENTE}

En la Facultad de Ciencias Naturales y Museo funciona el Instituto de Botánica C. Spegazzini el cual cuenta con el cepario fúngico más importante de Latinoamérica y además con el reconocimiento internacional (único en Argentina) para el depósito de cepas fúngicas para su estudio y posterior publicación en revistas científica internacionales. Se seleccionó como marcador de ambiente la cepa fúngica del hongo entomopatógeno Beauveria bassiana. (Figura 3) debido a que la misma no representa un riesgo para la salud humana, esto era de gran importancia, debido a que se debió permanecer en el interior del laboratorio por un lapso prolongado. 


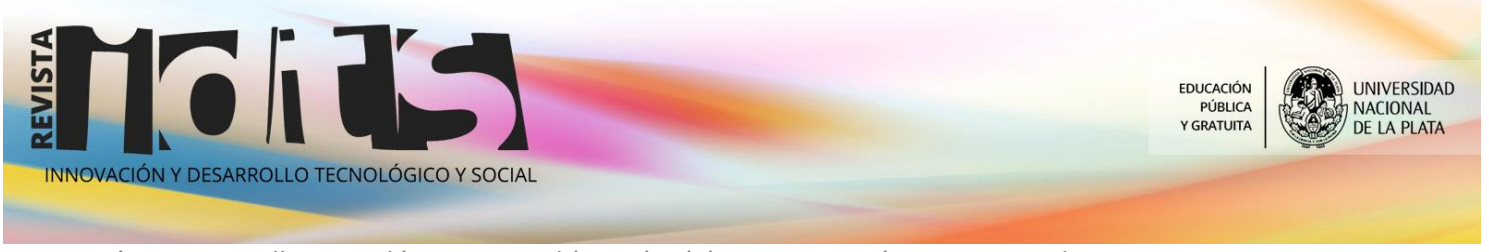

Innovación y Desarrollo Tecnológico y Social (2020) 2 (2): 167-203- Número especial COVID-19

Esta cepa presenta la característica de tener una muy elevada resistencia a la esterilización, una alta dispersión en el ambiente y no afecta a vertebrados.

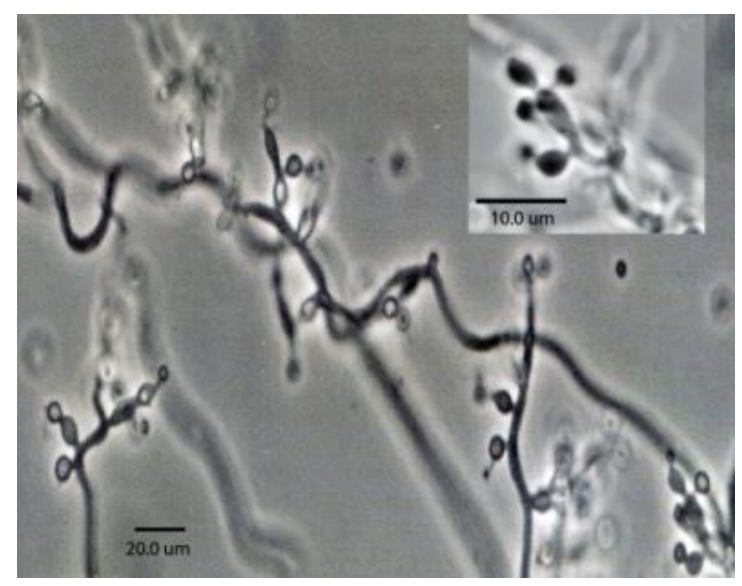

Figura 3. Cepa LPSc 1067 de Beauveria bassiana . Aspecto general y detalle de celula conidiogena holoblastica (Pelizza et al, 2010).

Figure 3. LPSc 1067 strain of Beauveria bassiana. General appearance and detail of holoblastic conidiogenous cell (Pelizza et al, 2010).

\section{Ensayo de laboratorio}

Se tomaron las dimensiones exactas del laboratorio para poder calcular el volumen en metros cúbicos que éste tiene. Las medidas obtenidas fueron de 8 metros con 80 centímetros de largo, por 7 metros con 60 centímetros de ancho, y 2 metros con 40 centímetros de alto. Dando como resultado, un volumen de 160,512 metros ${ }^{3}$. Seguidamente, se procedió al sellado hermético del laboratorio, colocando cinta de enmascarar en todos los marcos de puertas, ventanas y ductos de aire. El objetivo de esta maniobra estuvo destinada a construir un marco referencial de inicio sin 
que haya contaminación del exterior. Luego se colocó el equipo en una disposición central del laboratorio a 1 metro de altura.

\section{Dispersión de esporas fúngicas en el ambiente}

Antes de comenzar con el ensayo de laboratorio, primeramente, se procedió a dispersar a modo de spray una concentración de $1 \times 10^{8}$ conidios $/ \mathrm{ml}$ de esporas fúngicas del hongo entomopatógeno Beauveria bassiana, este procedimiento fue llevado a cabo para tener un ambiente en el cual, se encontrará una alta concentración de esporas, lo cual pondría en evidencia el correcto funcionamiento del esterilizador de aire UV-C prototipo Belerofonte.

\section{Medio de cultivo utilizado y tomas de muestras de aire}

El medio de cultivo utilizado para determinar la contaminación ambiental, fue Agar Papa Glucosa (APG), el cual fue elegido debido a que en él pueden crecer la mayoría de las esporas fúngicas, como así también distintas especies de bacterias que pudieran estar presentes en el ambiente. Se colocaron cápsulas de Petri en 4 grupos de 5 cápsulas cada uno, para tomar muestras de aire del ambiente en diferentes momentos, las mismas fueron colocadas de manera concéntrica con respecto al equipo. Todas fueron colocadas a 1 metro de altura. Las distancias a las que se colocaron las cápsulas fueron: 5 a 2 metros del equipo, 5 a 3 metros del equipo, 5 a 4 metros del equipo y 5 a 5 metros del equipo. El ensayo se llevó a cabo por el transcurso de 6 horas, tomando muestras de aire a Tiempo Cero (T0), es decir, luego de la dispersión de las esporas en el ambiente, y previo al encendido del equipo, y 
Innovación y Desarrollo Tecnológico y Social (2020) 2 (2): 167-203- Número especial COVID-19

luego a cada hora, durante 6 horas, en cada una de las distancias mencionadas anteriormente. La técnica de tomas de muestras de aire, consistió en abrir cada cápsula de Petri por un lapso de un minuto y luego cerrarla. Todas las muestras de aire que fueron tomadas ser rotularon y se colocaron en una estufa de cultivo por 5 días en oscuridad a $25^{\circ} \mathrm{C}$. Estas condiciones controladas, facilitan la germinación y el desarrollo de cualquier espora fúngica, o bacteriana que pudiera haber entrado en contacto con el medio de cultivo.

\section{Análisis Estadísticos}

Con los resultados obtenidos, se realizó un análisis de la varianza de dos vías para poder determinar si existen diferencias significativas en los resultados obtenidos, en lo que respecta a la descontaminación del ambiente por parte del prototipo BELEROFONTE II cuando se lo utilizo solo en la función de filtrado o cuando al prototipo se lo utilizo con las lámparas de tipo UV-C encendidas.

\section{2) Evaluación de los tiempos de específicos del uso de la luz UV-C, en la esterilización de esporas altamente resistentes}

Para poder determinar el tiempo mínimo necesario de exposición que necesitan las lámparas de tipo UV-C para eliminar microorganismos, se procedió a determinar la viabilidad de las esporas fúngicas, mediante la técnica descripta por Goettel e Inglis (1997). Para ello se procedió a preparar una suspensión de esporas fúngicas del hongo entomopatógeno $B$. bassiana de $1 \times 10^{4}$ conidios/ml de concentración. Por otro 
lado, se colocaron $800 \mu \mathrm{l}$ de medio de cultivo estéril de APG, en forma de una fina capa de aproximadamente $2 \mathrm{~mm}$ de espesor, sobre un portaobjetos (previamente esterilizado en autoclave), el cual se colocó en el interior de una cápsula de Petri que contenía un disco de papel de filtro estéril. Una cantidad de $300 \mu$ l de la suspensión fúngica mencionada anteriormente, se inoculó en el medio de cultivo. Posteriormente, esta suspensión fúngica fue sometida a las lámparas de radiación UV-C del prototipo Belorofonte II a distintos intervalos de tiempo 5-10-15-20-25 y 30 minutos. Luego se humedeció el papel de filtro que se encontraba en el interior de las cápsulas de Petri con $1 \mathrm{ml}$ de agua destilada estéril. Estas cápsulas de Petri fueron colocadas a $25^{\circ} \mathrm{C}$ y oscuridad dándole así las condiciones óptimas para permitir la germinación de las esporas. Al cabo de 24 horas, se determinó el número de esporas germinadas relacionadas con el número total de esporas. Se consideraron esporas germinadas cuando el tubo germinativo alcanzó la mitad de la longitud de las mismas. Se realizaron tres repeticiones por tratamiento y se contaron 300 esporas en cada caso.

\section{3) Pruebas con virus}

En la Facultad de Ciencias Veterinarias se encuentra el Laboratorio de Animales de Experimentación -UNLP. Dicho laboratorio cuenta con las instalaciones adecuadas para el manejo de diversas cepas virales además de ser un referente nacional e 


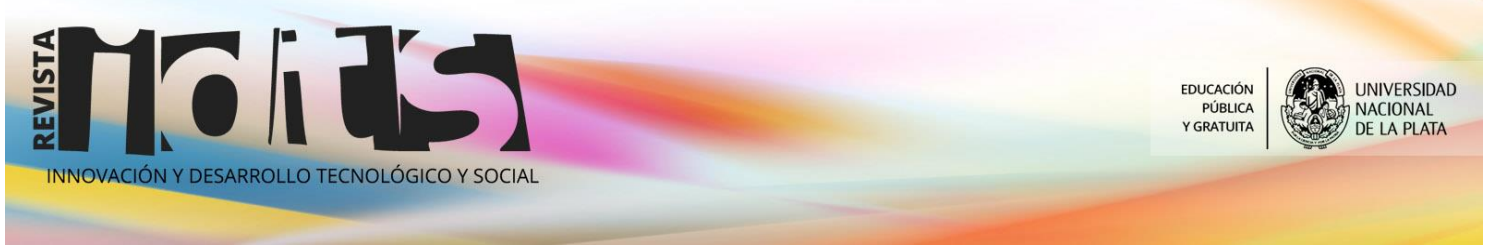

Innovación y Desarrollo Tecnológico y Social (2020) 2 (2): 167-203- Número especial COVID-19

internacional para experimentación sobre animales y estudio de diversos patógenos.

Se seleccionaron dos tipos de virus que debían tener características que sirvan como marco de referencia para lograr la inactivación del SARS-CoV-2.

Por un lado, se seleccionó el virus diminuto del ratón (Figura4) (MVMp, del inglés Minute virus of mice, cepa prototipo) forma parte de la familia Parvoviridae (del latín parvus $=$ pequeño) que incluye a virus que infectan a vertebrados e invertebrados. Las razones de elección de este virus fue su alta resistencia a la esterilización y manejo en un laboratorio de nivel de bioseguridad 2 (BSL2).

El MVMp, posee un tamaño de 20 a 30 Nm, el genoma es de ADN monocatenario de aproximadamente $5.5 \mathrm{~kb}$.
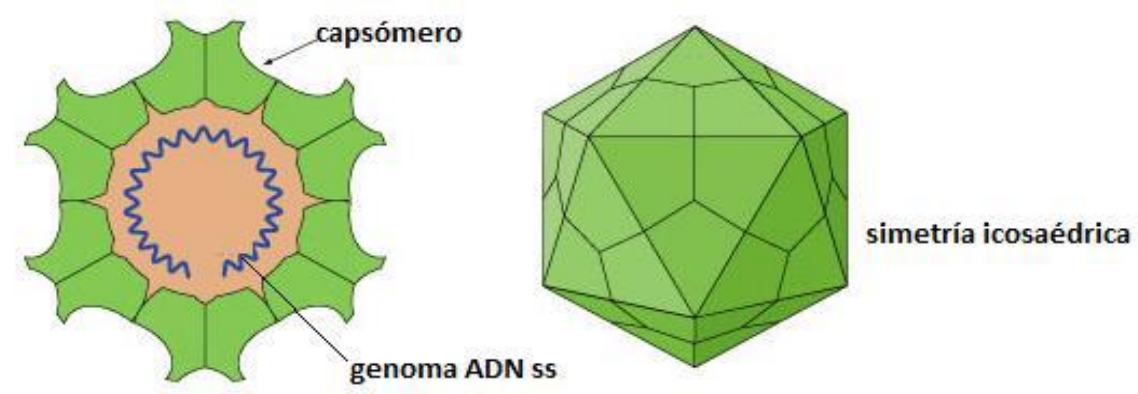

Figura 4. Esquema del MVMp, del inglés Minute virus of mice, cepa prototipo forma parte de la familia Parvoviridae.

Figure 4. Scheme of MVMp, from English Minute virus of mice, prototype strain is part of the Parvoviridae family. 


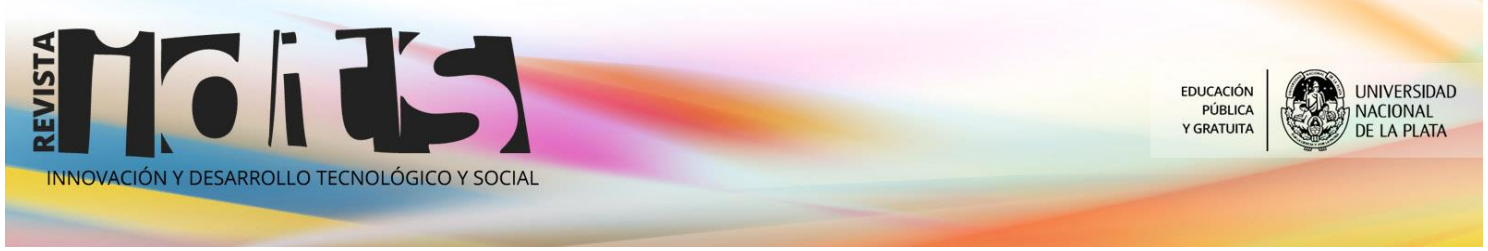

Innovación y Desarrollo Tecnológico y Social (2020) 2 (2): 167-203- Número especial COVID-19

Por otro lado, se seleccionó un virus con características morfológicas similares al SARS-CoV-2. Los Coronavirus han sido aislados de la mayoría de las especies animales evaluadas, incluyendo la humana. En el año 2003 un Coronavirus emergente fue identificado como agente etiológico del brote epidemiológico del SARS (Ksiazek et al, 2003) previo a este descubrimiento, los coronavirus humanos fueron asociados con infecciones respiratorias medias y altas en la temporada invernal.

El virus responsable del síndrome respiratorio del Medio Oriente (MERS), MERScoronavirus (CoV) es un linaje C-coronavirus similar al linaje murino $\beta$-coronavirus, el virus de la hepatitis del ratón (MHV) (Figura 5). El mismo es estructuralmente similar al MERS-CoV. Es un virus modelo ideal con el que estudiar los efectos de las radiaciones UV-C contra el SARS-CoV2 porque tiene muchas similitudes con el virus humano, pero, el virus murino puede manejarse en el laboratorio de nivel de bioseguridad 2 (BSL2).

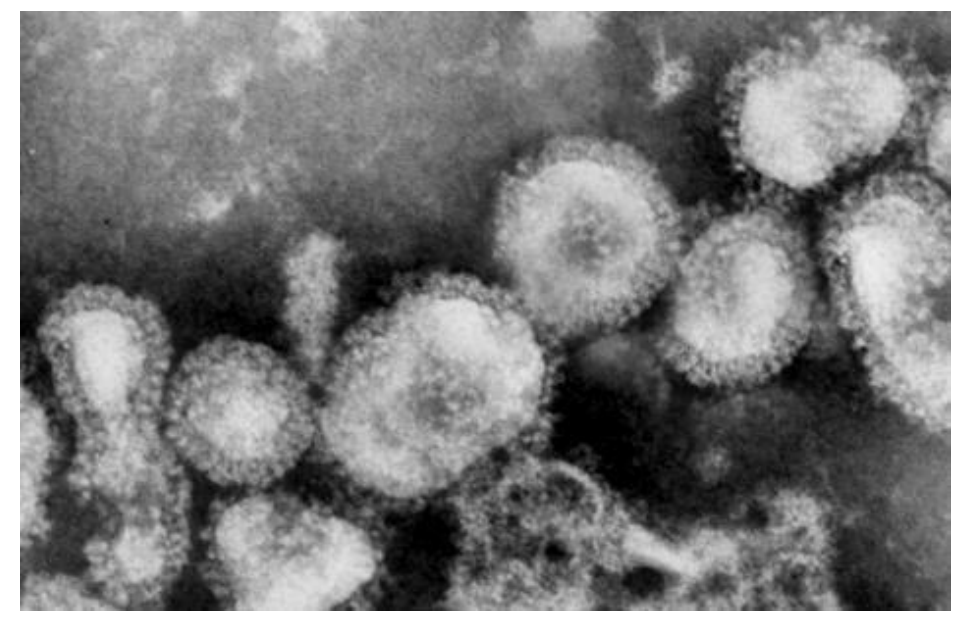

Figura 5. Microfotografia de virus "MHV". Figure 5. Photomicrograph of "MYHYV" virus. 
Innovación y Desarrollo Tecnológico y Social (2020) 2 (2): 167-203- Número especial COVID-19

2A) Las pruebas realizadas con el parvovirus se dividieron en dos etapas:

En una primera etapa se procedió a la conexión y funcionamiento del prototipo (ventiladores y luz UV-C 254 nm) durante 10 minutos y se colocó a $50 \mathrm{~cm}$ de distancia a la salida de aire del mismo un rectángulo $(20 \times 30 \mathrm{~cm})$ de tela filtrante como superficie receptora externa del flujo de aire proveniente del equipo. Luego se realizó una inoculación con un atomizador (10 ml) de una solución viral (HA 1/2048) de parvovirus murino (MVMp) en las tomas de aire del equipo. Durante el ensayo se dejó el equipo en funcionamiento (forzadores y luz UV-C) durante dos horas. Posteriormente, se procedió a desconectar el equipo y realizar la toma de muestras del filtro interior del aparato y tela filtrante receptora externa. Las muestras de los filtros se tomaron en un flujo laminar de clase I mediante el corte de sectores del material filtrante del filtro del equipo y tela filtrante externa al mismo. Las muestras se colocaron en tubos plásticos estériles (Nalgene) de $50 \mathrm{ml}$ y junto con el material de muestra remanente fueron almacenados a $-20^{\circ} \mathrm{C}$ hasta el momento de uso. La tela filtrante y la tela receptora se cortaron en pequeños pedazos y se procedió al análisis por técnica de la técnica de reacción en cadena de la polimerasa (PCR). Dado que en el filtro interno del equipo se detectaron partículas virales por PCR y para que los resultados fueran concluyentes se procedió a la segunda etapa.

Ensayo con animales. Se utilizaron 10 ratones machos de 8 semanas de edad de la cepa BALB/c separados en dos grupos de 5. Todos los individuos (dos grupos de 5 animales) se alojaron en microaisladores con provisión de agua 
y comida ad-libitum (en ambos grupos se utilizó como lecho de cama marlo de maíz triturado). En uno de los grupos se añadió en el lecho de cama tiras de muestras de material del filtro interno del equipo y que fue positivo (PCR) a MVMp para investigar si ocurre infección viral (en caso que el virus mantenga su infectividad). Para comprobar que el material entre en contacto con los animales y observar dispersión y mezcla del mismo en el lecho de cama, se dispuso su ubicación en un extremo de la caja. El otro grupo de 5 animales fue utilizado como grupo control (sin material de filtro en el lecho de cama). Se realizaron controles diarios para verificar el normal comportamiento de los ratones y a los 5 días, ambos grupos se sacrificaron con una mezcla de dióxido de carbono y oxígeno (70/30\%), para analizar heces y órganos en busca de evidencia de infección por parvovirus.

\section{B) Pruebas realizadas con el virus de la hepatitis de ratón (MHV).}

Se inició con la conexión y funcionamiento del prototipo (ventiladores y luz UV-C 254 $\mathrm{Nm}$ ) durante 10 minutos y se colocó a $50 \mathrm{~cm}$ de distancia a la salida de aire del mismo un rectángulo $(20 \times 30 \mathrm{~cm})$ de tela filtrante como superficie receptora externa del flujo de aire proveniente del equipo. Luego se realizó una inoculación con un atomizador $(10 \mathrm{ml})$ de una solución viral de coronavirus murino (MHV) en los conductos de aspiración de aire (ventiladores del equipo). Durante el ensayo se dejó 
el equipo en funcionamiento (ventiladores y luz UV-C) durante dos horas. Posteriormente se procedió a desconectar el equipo y realizar la toma de muestras del filtro interior del aparato y tela filtrante receptora externa. Las muestras se tomaron en un flujo laminar de clase 2 mediante el corte de sectores del material filtrante del filtro del equipo y tela filtrante externa al mismo. Las muestras se colocaron en tubos plásticos estériles (Nalgene) de $50 \mathrm{ml}$ y junto con el material de muestra remanente fueron almacenados a $-80^{\circ} \mathrm{C}$ hasta el momento de uso. Las muestras se analizaron por técnica de RT-PCR (retro transcriptasa-PCR).

\section{Resultados}

\section{1) Evaluación de pruebas de esterilización de ambiente con el prototipo}

\section{Belerofonte II}

Se observó una disminución progresiva de la carga de esporas fúngicas presentes en el aire del laboratorio del Instituto de Botánica Spegazzini.

En este ensayo se pudo observar que, si bien el prototipo Belorofonte II fue muy efectivo para descontaminar el aire del laboratorio, sin encender las lámparas de radiación UV-C, la rapidez y eficacia en lograr este objetivo, se incrementan cuando dichas lámparas son encendidas. Por otro lado, vemos que la descontaminación del ambiente no depende de la distancia a la cual se toman las muestras de aire del equipo, ya que logra una descontaminación total del aire del ambiente al cabo de 6 horas, ya sea que las muestras de aire sean tomadas a 2 metros o a 5 metros de 
Innovación y Desarrollo Tecnológico y Social (2020) 2 (2): 167-203- Número especial COVID-19

distancia del equipo. Los análisis estadísticos nos muestran que existen diferencias significativas entre utilizar o no las lámparas UV-C encendidas, como así también en lo que respecta al tiempo de funcionamiento del equipo (Figura 6). No se observaron diferencias significativas en lo que respecta a la distancia a la cual se toman las muestras (Figura 7).

En los resultados para determinar la capacidad de filtrado de partículas ambientales por parte del prototipo observamos una capacidad de filtrado muy buena por parte del equipo, aún sin que se encendieran las luces de radiación UV-C, debido a que se pasó de un promedio de 23 colonias fúngicas por cápsula de Petri que pertenecían al control previo al encendido del equipo, a 0,1 colonias fúngicas en promedio luego de que el equipo funcionara durante un lapso de 6 horas.

\section{Ensayo sin luz}

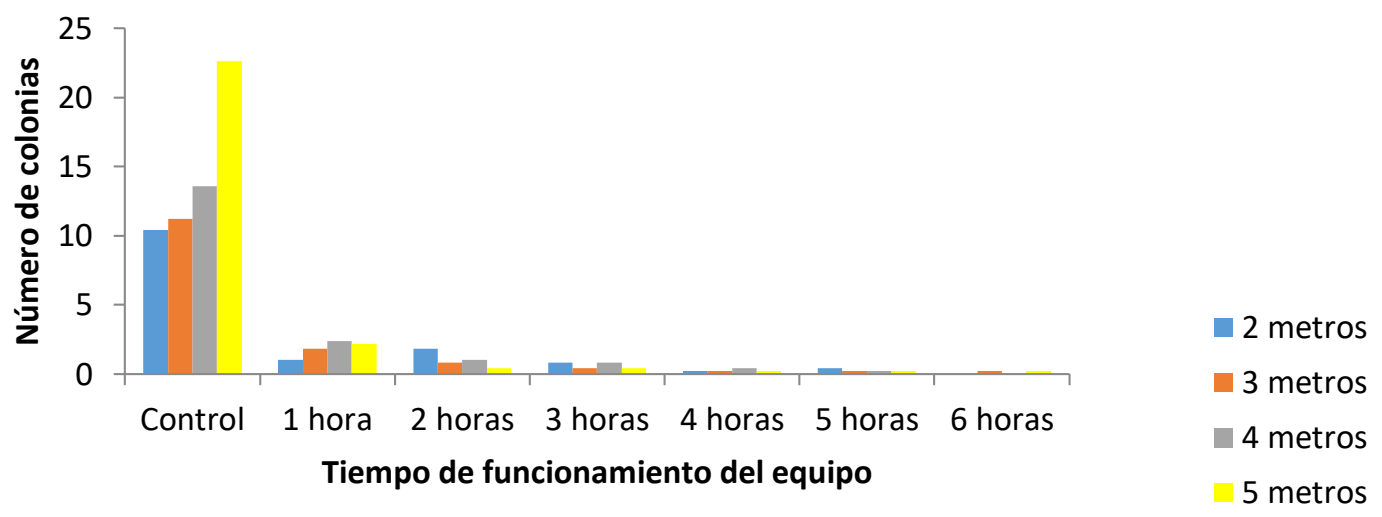

Figura 6: Número promedio de colonias fúngicas, a través del tiempo, tomadas a una distancia que va desde los $\mathbf{2}$ metros hasta los 5 metros de distancia del prototipo. El equipo no tenía las luces UV-C encendidas, solo trabajaba en la función de filtrado. 
Figure 6 (previous page): Average number of fungal colonies, over time, taken at a distance ranging from 2 meters to 5 meters away from the prototype. The equipment did not have the UV-C lights on, it was only working in the filtering function.

Resultados similares fueron observados, cuando se utilizó el prototipo con las luces de tipo UV-C encendidas. Los números de colonias fúngicas disminuyeron en promedio de un valor de 11,2 colonias por cápsula de Petri en el control ambiental previo (antes de que se encendiera el equipo), a un valor de 0 colonias fúngicas por capsulas de Petri al cabo de 6 horas de funcionamiento del equipo (Figura 7).

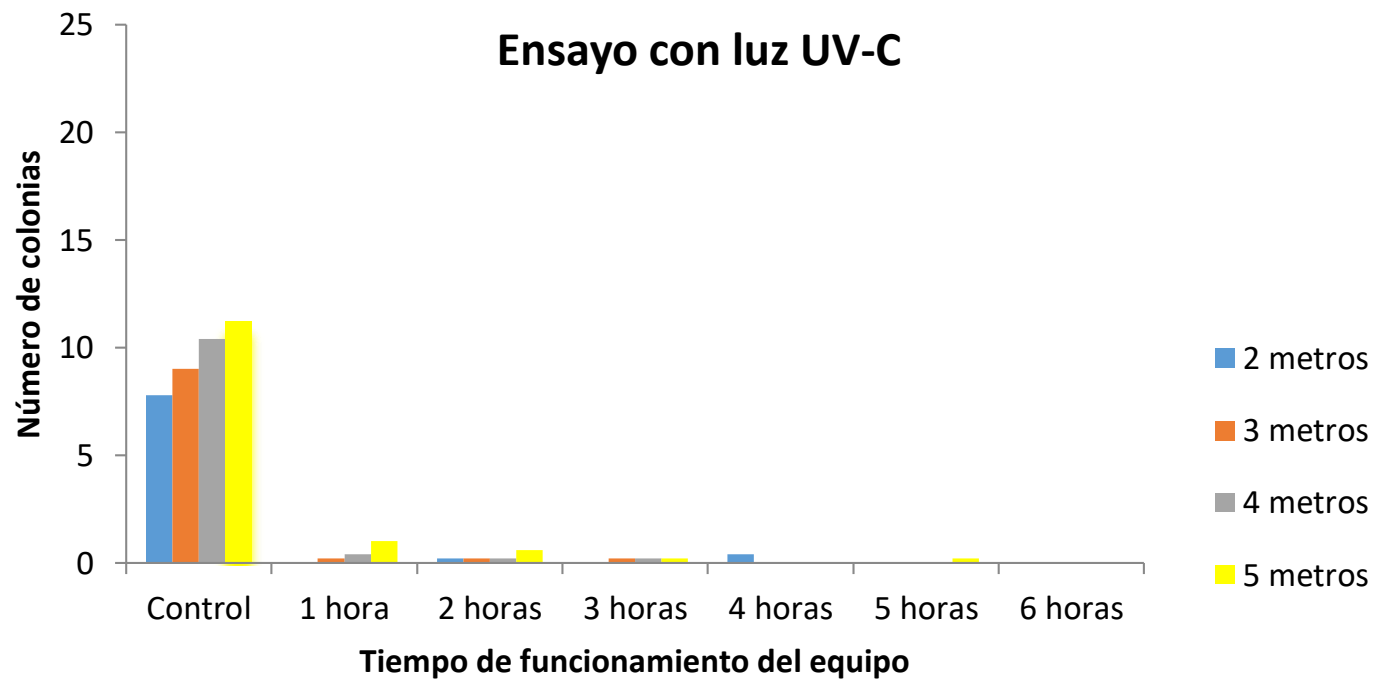

Figura 7. Número promedio de colonias fúngicas, a través del tiempo, tomadas a una distancia que va desde los $\mathbf{2}$ metros hasta los $\mathbf{5}$ metros de distancia del prototipo. El equipo tenía las luces UV-C encendidas.

Figure 7. Average number of fungal colonies, over time, taken at a distance from 2 meters to 5 meters from the prototype. The equipment had the UV-C lights on. 
El análisis de la varianza, demostró que existen diferencias significativas ( $D F=1 ; F=$ 37,97; $\mathrm{P}<0,0001)$, entre utilizar el equipo con las lámparas UV-C encendidas 0 apagadas. Según este análisis estadístico, la utilización de las lámparas UV-C mejora el rendimiento en lo que respecta a la esterilización del aire del ambiente por parte del equipo (Tabla 1).

Tabla 1: Resultados del Análisis de varianza de dos vías, para el ensayo realizado con el prototipo Belorofonte II, con las lámparas de tipo UV-C apagadas y encendidas, a distancias que fueron de los $\mathbf{2}$ a 5 metros y a distintos intervalos de tiempo los cuales fueron de tiempo 0 (control previo) a 6 horas de actividad del equipo. Diferencias significativas se establecen cuando el valor de $P<0,0001$.

Table 1: Results of the two-way analysis of variance, for the test carried out with the Belorofonte II prototype, with the UV-C type lamps turned off and on, at distances that ranged from 2 to 5 meters and at different time intervals, which were from time 0 (previous control) to 6 hours of team activity. Significant differences are established when the value of $P<0.0001$.

\begin{tabular}{llll}
\hline Variables & DF & F & P \\
\hline Tratamiento & 1 & 37,97 & $<0,0001$ \\
Tiempo & 5 & 16,10 & $<0,0001$ \\
Distancia & 3 & 0,47 & 0,7016 \\
Tratamiento*Tiempo & 5 & 6,45 & $<0,0001$ \\
Tratamiento*distancia & 3 & 1,13 & 0,3398 \\
Tiempo*distancia & 15 & 1,46 & 0,1234 \\
Tratamiento*Tiempo*distancia & 15 & 0,92 & 0,5409 \\
\hline
\end{tabular}


Además se observaron diferencias significativas ( $D F=5 ; F=16,10 ; P<0,0001$ ) en lo que respecta al tiempo que se mantiene encendido el equipo. Es decir, a medida que pasa el tiempo, mejor se produce la esterilización del aire, llegando a un tiempo de 6 horas en los cuales ya no se registran esporas fúngicas contaminantes presentes en el ambiente. Por último, se observaron diferencias significativas en la interacción tratamiento*tiempo $(\mathrm{DF}=5 ; \mathrm{F}=$ 6,45; P <0,0001), esto nos está indicando, que hay una relación directa entre el encendido o no de las lámparas UV-C y la cantidad de horas que se deja funcionando al equipo (Tabla 1).

2) Evaluación de los tiempos de específicos del uso de la luz UV-C, en la esterilización de esporas altamente resistentes

Se observó que el tiempo mínimo de exposición a las lámparas UV-C debe ser de 30 minutos, para que se elimine el 100\% de las esporas fúngicas que fueron expuestas a dicha radiación de manera directa (Figura 8 y Figura 9). 


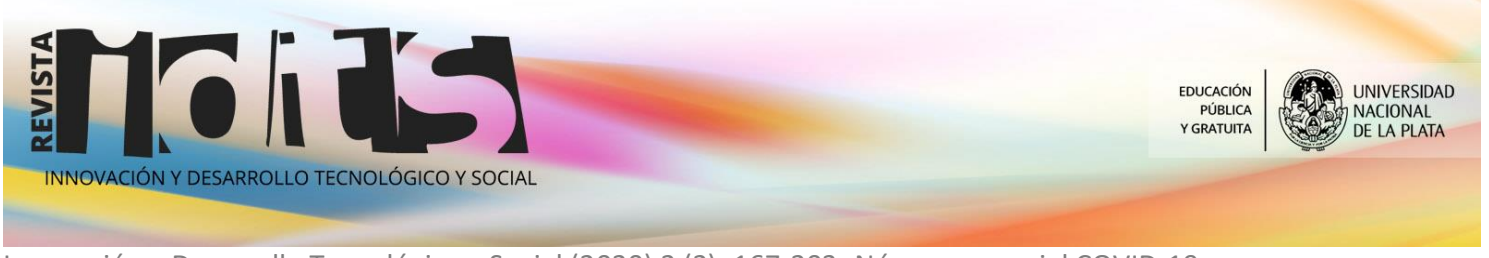

Innovación y Desarrollo Tecnológico y Social (2020) 2 (2): 167-203- Número especial COVID-19

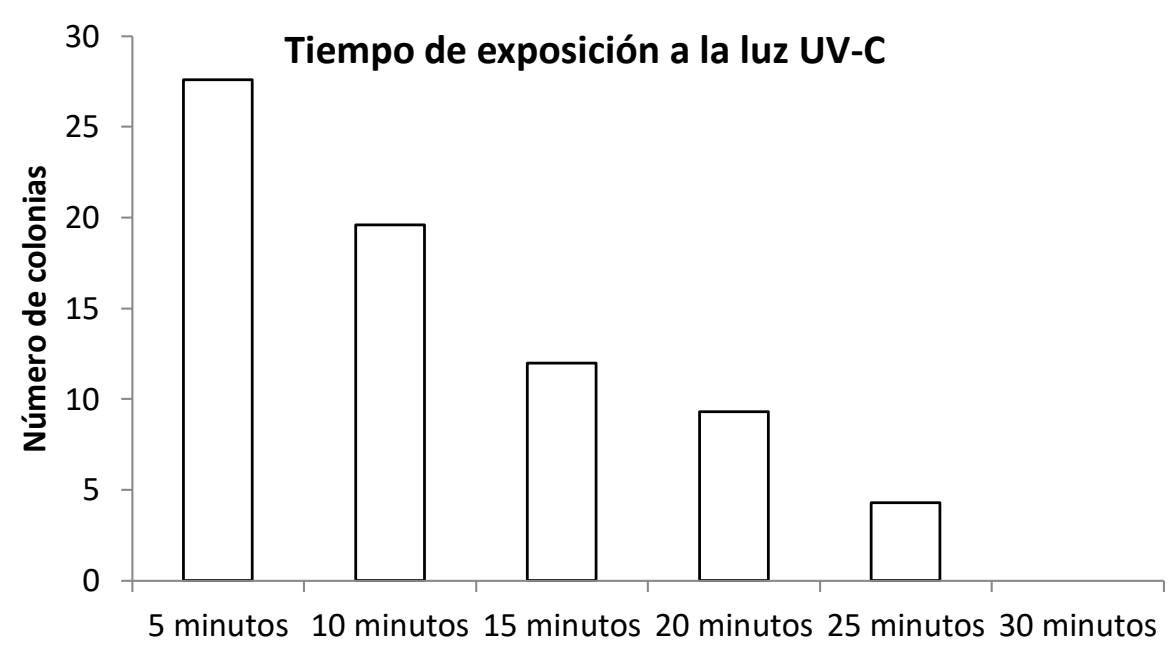

Tíempo

Figura 8: Tiempo mínimo de exposición a la radiación de las lámparas UV-C, para eliminar la totalidad de las esporas fúngicas de Beauveria bassiana.

Figure 8: Minimum time of exposure to radiation from UV-C lamps, to eliminate all the fungal spores of Beauveria bassiana.

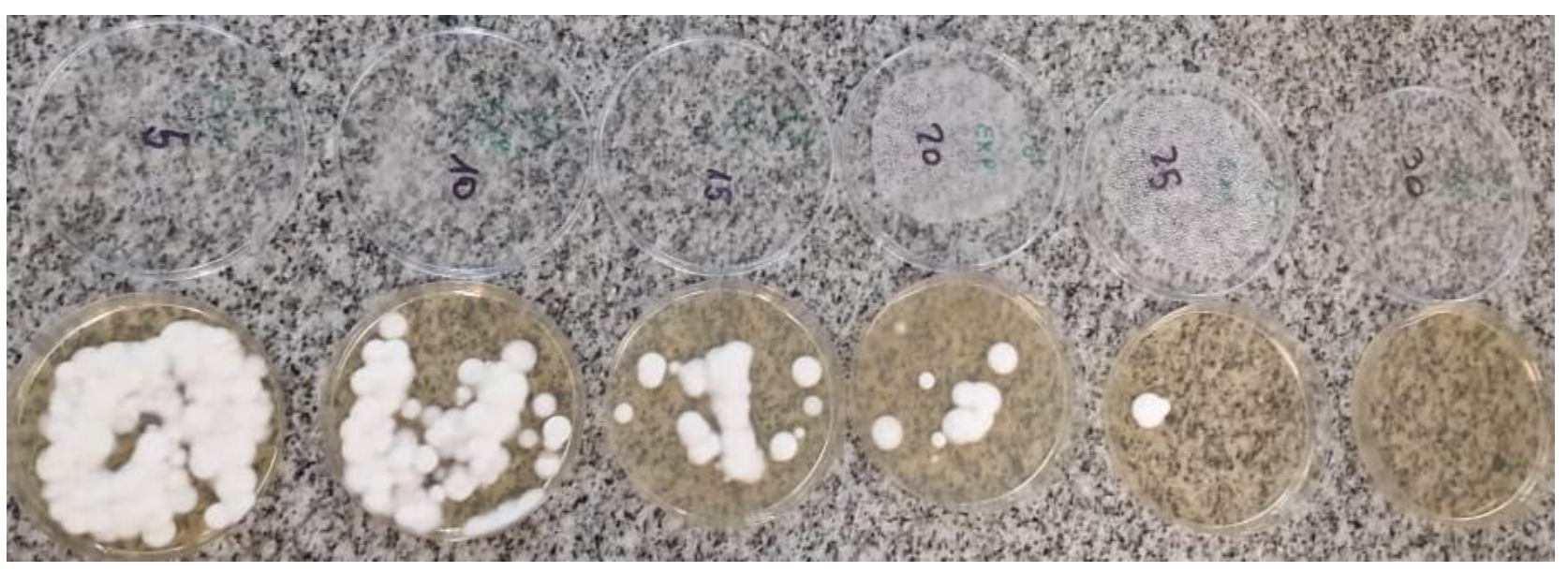

Figura 9: Tiempo de exposición a la luz UV-C en minutos.

Figure 9: Exposure time to UV-C light in minutes. 


\section{3- $\quad$ Resultados de pruebas sobre virus con el prototipo Belerofonte II}

\section{3- A) Técnica de PCR en las muestras del equipo inoculado con Parvovirus} (MVMp.)

Al analizar el comportamiento de los primers, se demostró que obtuvo un buen desempeño en ambas rondas de PCR en el rango de temperatura empleado. Obteniéndose una banda de 1090 pb para parvovirus genérico y 640 pb virus diminuto del ratón (MVMp). En ningún caso se observó amplificación en el control negativo (agua en lugar de molde). Del total de muestras analizadas se obtuvieron resultados positivos para MVMp en la muestra viral utilizada en la inoculación y en el filtro interno del equipo. No se detectó ADN de MVMp en la muestra de la tela filtrante externa al equipo (Figura 10).

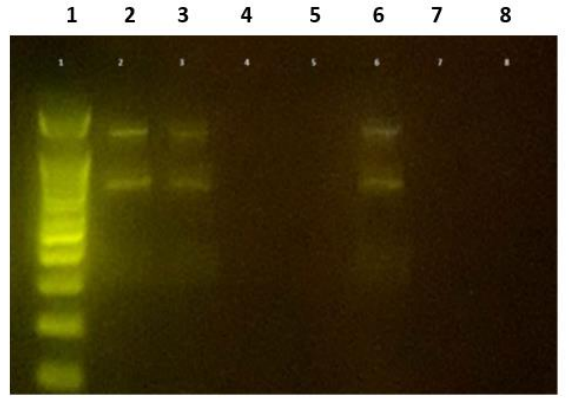

Figura 10. Técnica de sn-PCR: gel de agarosa al 1,5\%. Se muestra una banda específica para el virus diminuto del ratón (MVMp), de acuerdo con el tamaño esperado (640pb) y para parvovirus genérico (1090pb). Línea 1: marcador de peso molecular de 100pb (Promega); Líneas 2 y 3: muestras positivas (inóculo de MVMp y filtro interno respectivamente); Línea 4: muestra negativa (tela filtrante externa); Línea 5 control negativo (agua libre de nucleasas); Línea 6 control positivo (ADN de cepa MVMp); Líneas 7 y 8: sin muestra. 
Figure 10 (previous page). Sn-PCR technique: 1.5\% agarose gel. A specific band is shown for mouse tiny virus (MVMp), according to the expected size (640bp) and for generic parvovirus (1090bp). Lane 1: 100bp molecular weight marker (Promega); Lines 2 and 3: positive samples (MVMp inoculum and internal filter respectively); Line 4: negative sample (external filter cloth); Line 5 negative control (nuclease free water); Line 6 positive control (MVMp strain DNA); Lines 7 and 8: no sample.

Según los resultados positivos obtenidos en el filtro interno del equipo, se realizó una segunda prueba con animales, para observar si se trataba de partículas virales inactivas o virus con capacidad de infección en ratones.

Para esto se recortaron fragmentos del filtro interno, y se colocaron como lecho de cama en la jaula con ratones. Los animales se dejaron durante 5 días en contacto con el lecho de cama. Luego se realizó eutanasia en los ratones y se tomaron muestras de bazo, íleon y materia fecal, para control de parvovirus por PCR (Figura 11 y 12)

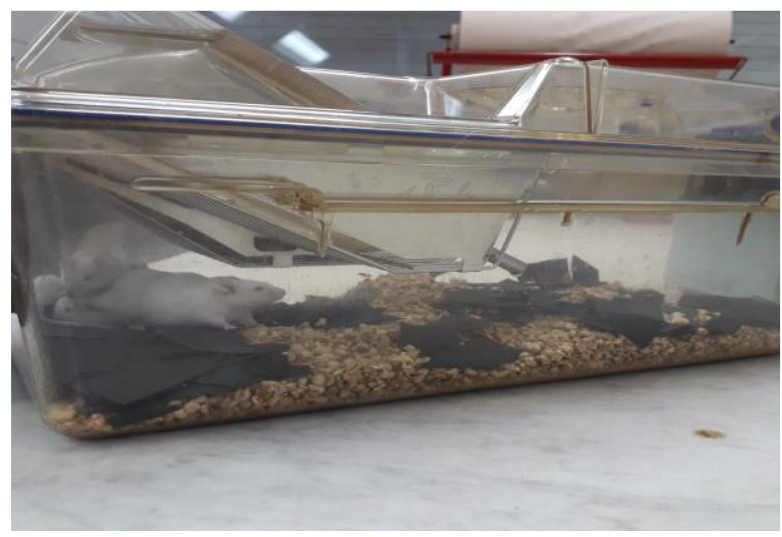

Figura 11. Grupo de 5 ratones a los cuales se les añadió en el lecho de cama material del filtro interno del equipo y que fue positivo a MVMp. 


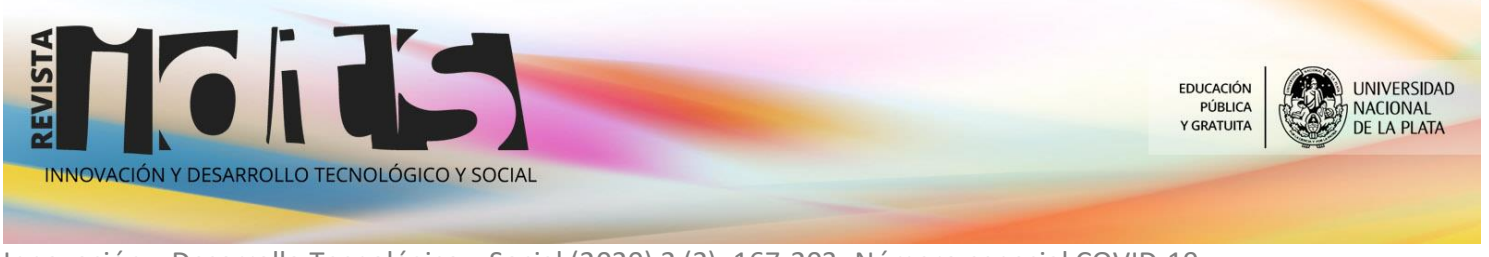

Innovación y Desarrollo Tecnológico y Social (2020) 2 (2): 167-203- Número especial COVID-19

Figure 11 (previous page). Group of 5 mice to which material from the internal filter of the equipment was added to the bedding and which was positive for MVMp.
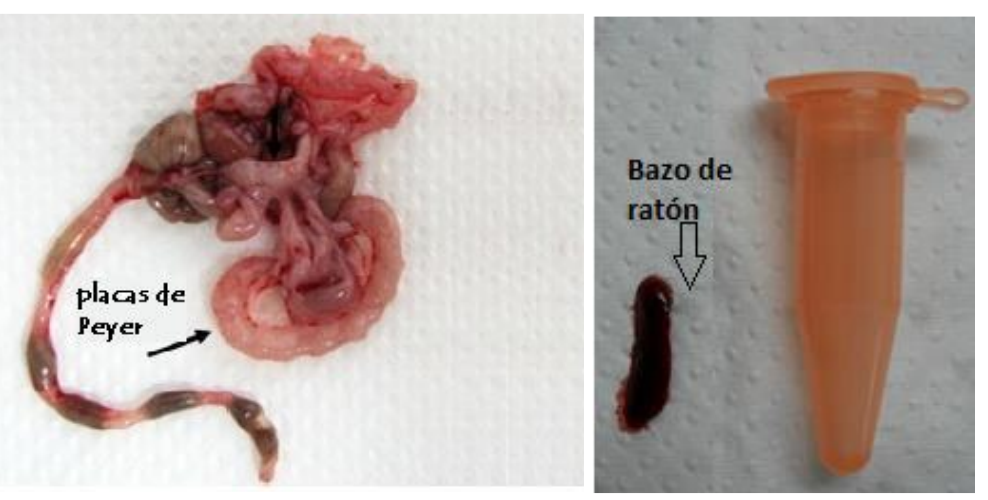

Figura 12. Bazo y región del íleon (Placas de Peyer) de un ratón utilizado en la toma de muestras y extracción de ADN.

Figure 12. Spleen and ileum region (Peyer's patches) of a mouse used in DNA sampling and extraction.

Ensayo de infectividad viral en ratones con material filtrante del equipo y positivo mediante PCR a MVMp

Del total de muestras analizadas se obtuvieron resultados positivos para MVMp en la muestra del filtro interno del equipo mezclado con el lecho de cama. No se detectó ADN de MVMp en las muestras de bazo, íleon y materia fecal de los ratones expuestos al lecho de cama contaminado con parvovirus (Figura 13) 


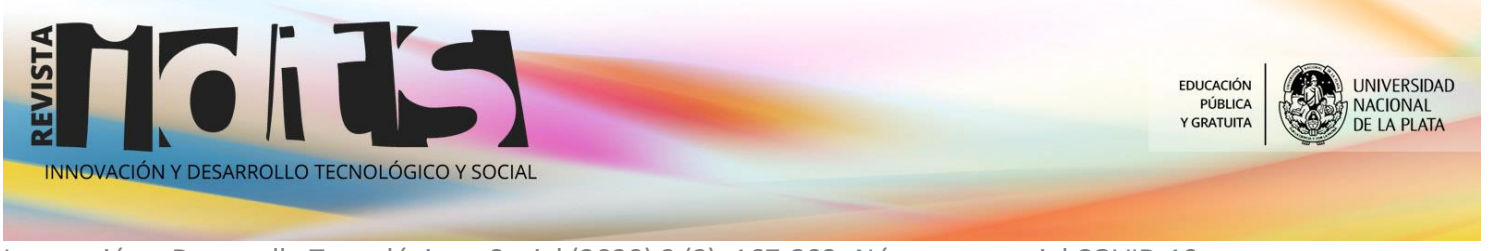

Innovación y Desarrollo Tecnológico y Social (2020) 2 (2): 167-203- Número especial COVID-19

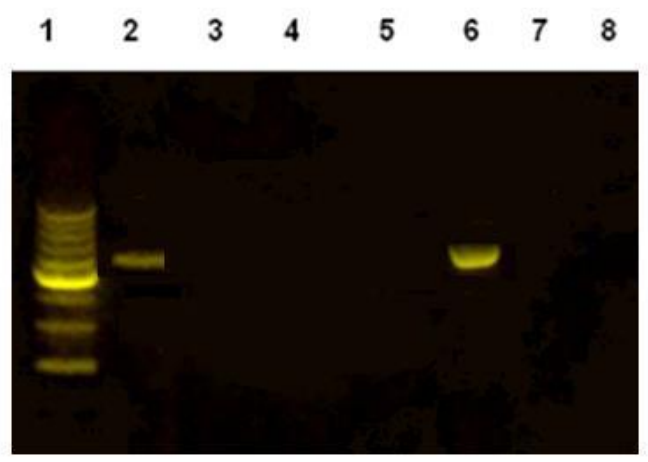

Figura 13. Técnica de sn-PCR: gel de agarosa al 1,5\%. Línea 1: marcador de peso molecular de 100pb (Promega); Línea 2: muestra positiva a MVMp (material de filtro interno en el lecho de cama) muestra una banda específica para el virus diminuto del ratón (MVMp), de acuerdo con el tamaño esperado (640pb); Línea 3: muestra íleon y bazo de ratón negativa a MVMp; Línea 4: muestra de materia fecal negativa a MVMp; Línea 5: control negativo (agua libre de nucleasas); Línea 6: control positivo (ADN de cepa MVMp) muestra una banda específica para el virus diminuto del ratón (MVMp), de acuerdo con el tamaño esperado (640pb); Líneas 7 y 8: sin muestra.

Figure 13. Sn-PCR technique: 1.5\% agarose gel. Lane 1: 100bp molecular weight marker (Promega); Line 2: sample positive for MVMp (internal filter material in the bedding) shows a specific band for the tiny virus of the mouse (MVMp), according to the expected size (640bp); Line 3: shows MVMp negative mouse ileum and spleen; Line 4: MVMp negative stool sample; Line 5: negative control (nuclease free water); Line 6: positive control (MVMp strain DNA) shows a specific band for mouse tiny virus (MVMp), according to the expected size (640bp); Lines 7 and 8: no sample.

3-B) Técnica de RT-PCR en las muestras del equipo inoculado con el Virus de la hepatitis del ratón (MHV).

Al analizar el comportamiento de los primers, se demostró que tuvieron un buen desempeño de RT-PCR en el rango de temperatura empleado. Obteniéndose una 
banda de 500 pb. En ningún caso se observó amplificación en el control negativo (agua en lugar de molde).

Del total de muestras analizadas se obtuvo resultado positivo para MHV en la muestra viral utilizada en la inoculación para prueba del equipo. No se detectó ADN de MHV en las muestras analizadas de filtro interno y de la tela filtrante externa al equipo luego de transcurridas dos horas de funcionamiento del mismo.

Los resultados encontrados indican que MHV tuvo resultados positivos (RT-PCR) en la muestra de la solución viral utilizada para inocular en el aparato germicida UV-C. Las muestras del interior (filtro interno) y exterior (tela filtrante) del equipo fueron negativas al virus una vez finalizado el tiempo de exposición ( 2 horas) de irradiación con UV-C.

El uso del sistema de desinfección UV-C puede prevenir la propagación nosocomial del virus y proteger al personal en el proceso. En el ensayo realizado y luego de dos horas de irradiación UV-C, no se pudieron obtener resultados positivos a MHV en las muestras de tela filtrante interna y externa (la última colocada a $50 \mathrm{~cm}$ de la salida del aire) del equipo, aunque se tenía conocimiento de que el filtro interno del equipo no posee una trama de porosidad inferior a $100 \mathrm{Nm}$ (tamaño promedio de los coronavirus). El tamaño promedio de una partícula de coronavirus es menor que el límite de 0.3 micras para los filtros más eficientes HEPA (High Efficiency Particulate Air). Sin embargo, durante la entrevista con los expertos responsables del diseño y construcción del equipo, se pudo conocer que el material del filtro interno posee 
una membrana hidrofóbica que pudo funcionar como una barrera durante el ensayo, y donde las microgotas de la solución viral transportadas por el flujo de aire pudiesen ser retenidas hasta lograr una inactivación y/o destrucción de las partículas virales por radiación UV-C (Figura 14).

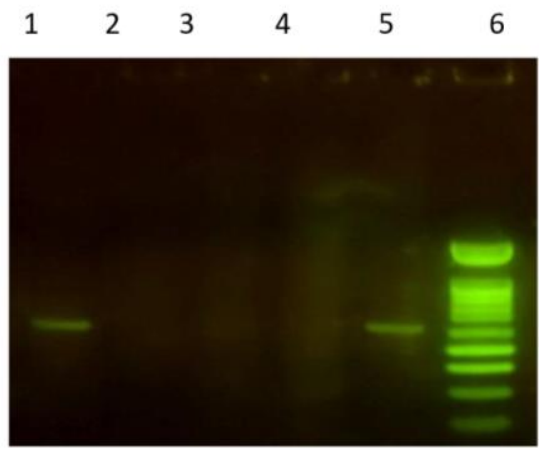

Figura 14. Técnica de PCR: gel de agarosa al 1,5\%. Se muestra una banda específica para el coronavirus de la hepatitis del ratón (MHV), de acuerdo con el tamaño esperado (500pb) Línea 1: muestra positiva (inóculo de MHV); Línea 2: muestra negativa (tela filtrante interna); Línea 3: muestra negativa (tela filtrante externa); Línea 4: control negativo (agua libre de nucleasas); Línea 5 control positivo (ADN de MHV); Línea 6: marcador de peso molecular de 100pb (Promega).

Figure 14 (previous page). PCR technique: 1.5\% agarose gel. A specific band for the mouse hepatitis coronavirus (MHV) is shown, according to the expected size (500bp). Line 1: positive sample (MHV inoculum); Line 2: negative sample (internal filter cloth); Line 3: negative sample (external filter cloth); Line 4: negative control (nuclease free water); Positive control line 5 (MHV DNA); Line 6: 100bp molecular weight marker (Promega)

\section{DISCUSIÓN}

Al realizar un relevamiento de los datos relacionados con la problemática de la transmisión por vía aérea del SARS-COV-2 se encontró evidencia científica que 
correlaciona la presencia de micro gotas en el ambiente y el COVID-19 (Fennelly, 2020). Se reconoce cada vez más la transmisión aérea del virus (Asadi et al, 2020). Esto alentaría a la utilización de equipos de esterilización de ambientes, como el que se presenta en este trabajo.

\section{Evaluación del equipo}

En las experiencias previas a los ensayos de laboratorio resultó difícil calibrar el nivel de retención que producía el equipo con respecto a los flujos de aire. Una vez calibrado el prototipo (BELEROFONTE I) este demostró tener un buen desempeño en ambientes de 160 metros cúbicos, lográndose ambientes totalmente depurados entre 12 a 18 horas.

Con respecto a la relación hombre máquina el equipo no significo ningún riesgo para la integridad del personal que ejecutó los ensayos de laboratorio. Desde el punto de vista ergonómico el equipo requería modificaciones.

Con el prototipo (BELEROFONTE II) se mejoró el desempeño lográndose ambientes de 160 metros cúbicos totalmente depurados aproximadamente a las 6 horas sin riesgo para los pacientes y/o el personal de la salud. En el equipo final se solucionó el aspecto ergonómico lográndose reducir el tamaño del mismo y mejorando su rendimiento. 
Innovación y Desarrollo Tecnológico y Social (2020) 2 (2): 167-203- Número especial COVID-19

\section{Evaluación de los ensayos de laboratorio}

Se realizaron un total de 5 pruebas de ambiente en el Instituto Spegazzini evaluando distintos aspectos: nivel de filtrado por parte de los filtros, eficacia de la luz UV-C sobre cultivos y eficacia en lo que respecta a la depuración y esterilización del aire del ambiente. Los medios de cultivo se prepararon y manipularon hasta su uso, en cámaras de flujo laminar grado 2 y en condiciones de esterilidad descartando de este modo contaminación cruzada de los medios de cultivo.

En el Laboratorio de Animales de Experimentación se realizaron 3 pruebas, 2 directas sobre el equipo (principalmente sobre los filtros internos y tela filtrante externa a la salida del equipo) y una indirecta sobre animales haciendo convivir a los animales con partes del filtro.

Los primers de las PCR tuvieron un buen comportamiento en el rango de temperatura empleado.

El ensayo indirecto sobre animales y el diseño experimental fue supervisado y aprobado por el Comité Institucional para el Cuidado y Uso de Animales de Laboratorio (CICUAL) de la Facultad de Ciencias Veterinarias de la UNLP, bajo el código $\mathrm{N}^{\circ}$ 105-5-20P. Todos los procedimientos con animales se realizaron de acuerdo con los principios éticos para el uso de los animales de laboratorio del Consejo de Organizaciones Internacionales de Ciencias Médicas (CIOMS). 


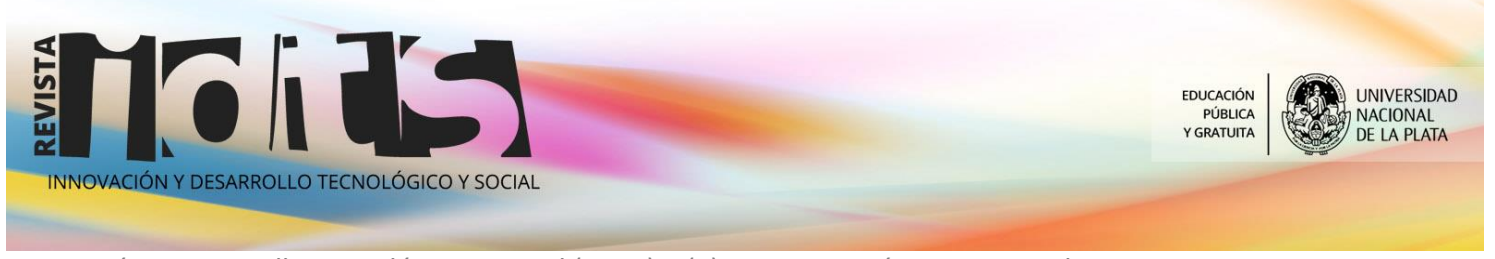

Innovación y Desarrollo Tecnológico y Social (2020) 2 (2): 167-203- Número especial COVID-19

\section{CONCLUSIONES}

Dentro de los límites de la presente publicación se puede concluir:

1) En lo que respecta a la esterilización de ambientes, los filtros utilizados dentro del equipo han permitido retener la mayor cantidad de partículas infecciosas, sin la utilización de luz UV-C, y producir aire estéril a la salida del equipo, lo cual demuestra la eficacia de los filtros incorporados.

2) Cuando se utilizó el equipo en función filtrado más el uso de la luz UV-C, se observaron mejores resultados en cuanto a la calidad de aire que sale del equipo.

3) En cuanto a los tiempos de esterilización por luz UV-C, se establecieron en 30 minutos, y considerando la capacidad de filtrado del equipo en sí, podría proponerse un esquema de 5 horas de uso, donde 4:30 horas sean solo de filtrado, y luego se usen las luces UV-C por 30 minutos. Esto tendría particular interés, si se utilizaran lámparas UV-C que producen Ozono, para que el funcionamiento de las mismas no supere los límites de seguridad.

4) El desarrollo propuesto, permite descontaminar el aire del ámbito de trabajo en forma segura rápida y continua, pudiendo estar el profesional y paciente presente durante dicho proceso, cosa que no es posible con las luz UV-C directa, por los riesgos a la salud que conlleva (Salomon, 2020), lo cual instaura una nueva lógica en lo que respecta a bioseguridad y disminuye el riesgo de contagio de cualquier patógeno que pueda transmitirse ya sea por vía aérea directa o a través de gotículas en suspensión. 
5) En cuanto a las pruebas de virología, el equipo fue altamente efectivo en neutralizar dos tipos de virus diferentes.

6) En las pruebas con parvovirus de ratones, que es un virus ADN, de la familia Parvoviridae, y que es 5 veces más pequeño que el SARS-Cov-2, y además es alcohol resistente, mostro resultados muy efectivos. Incluso cuando en los filtros internos se detectó ADN Viral, en las pruebas con animales se demostró que eran Virus Inactivos, sin capacidad de infectar.

7) En las pruebas con el virus de la hepatitis murina ( $\beta$-coronavirus de la misma familia del SARS- CoV-2), que es un virus ARN, se comprobó la total eliminación del mismo en las pruebas realizadas.

\section{Teniendo todas estas conclusiones expresadas, podríamos decir, a modo de} recomendación, que:

Existe una clara correlación entre el COVID-19 y la vía de transmisión aérea. En base a la información obtenida en los ensayos de laboratorio el equipo desarrollado es una herramienta contundente en lo que respecta a eliminación de microorganismos presentes en el ambiente al cabo de 6 horas de funcionamiento, cuando estos están en suspensión lográndose valores de esterilidad del aire del 99\% en unas 6 horas de funcionamiento.

1) Si bien no se pudo probar la eficacia del equipo sobre el SARS-CoV-2 por cuestiones de bioseguridad, se realizaron ensayos sobre virus como el parvovirus 
del ratón (virus resistente a agentes físicos ambientales), como también con un $\beta$ coronavirus como el virus de la hepatitis del ratón similar al virus responsable del síndrome respiratorio del Medio Oriente (MERS), MERS-coronavirus (CoV) que es un linaje C-coronavirus similar al linaje murino. El mismo es estructuralmente similar al MERS-CoV. Es un virus modelo ideal con el que estudiar los efectos de las radiaciones UV-C contra el SARS-CoV2.

2) La conjugación de las características de ambos virus y los resultados obtenidos nos dan la certeza de que cualquier partícula viral de SARS-CoV2 que sea aspirado por el equipo quedara retenida e inactivada rápidamente.

3) Cuando se seleccionó el hongo entomopatógeno Beauveria bassiana para contaminar el aire de un ambiente, se pensó en esto porque se quería comprobar si el equipo era eficiente para eliminar no solo el SARS-CoV-2 sino también cualquier otro microorganismo presente en el ambiente. Dicha espora es una de las formas de vida más resistentes y su grado de dispersión en el ambiente es muy alta. A pesar de que no representa ningún peligro para la vida humana es un marcador excelente para establecer no solo el grado de depuración de un ambiente, sino que también sirvió para establecer el poder de esterilización que se obtuvo con el equipo desarrollado.

4) En ambientes altamente contaminados con cualquier tipo de patógeno la utilización del equipo en su configuración correcta (equipo /metros cúbicos) es una herramienta que protege indudablemente a las personas. 
5) Por todo lo expuesto anteriormente se puede concluir que la utilización sistemática y el establecimiento de este tipo de aparatología como protocolo de protección puede disminuir los índices epidemiológicos de la pandemia en curso a causa del SARS-CoV-2, y disminuir los índices epidemiológicos de otras afecciones principalmente respiratorias.

\section{Financiamiento}

UNLP - Incubadora de Proyectos Minerva.

\section{Referencias bibliográficas}

Asadi, S., Bouvier, N., Wexler, A. S., \& Ristenpart, W. D. (2020). The coronavirus pandemic and aerosols: Does COVID-19 transmit via expiratory particles?. Aerosol science and technology : the journal of the American Association for Aerosol Research, 0(0), 1-4. https://doi.org/10.1080/02786826.2020.1749229

Fennelly, K. P. (2020). Particle sizes of infectious aerosols: implications for infection control. The Lancet. Respiratory Medicine, 8(9), 914-924. https://doi.org/10.1016/S2213-2600(20)30323-4

Goettel, M.S. e Inglis, D.G. (1997). Fungi: Hyphomycetes. In: Lacey, L.A. (ed.) Manual of techniques in insect pathology. London, UK, Academic Press, 213-249.

\section{https://www.ncbi.nlm.nih.gov/pmc/articles/PMC7250761/pdf/main.pdf}

Ksiazek, T. G., Erdman, D., Goldsmith, C. S., Zaki, S. R., Peret, T., Emery, S., Tong, S., Urbani, C., Comer, J. A., Lim, W., Rollin, P. E., Dowell, S. F., Ling, A. E., Humphrey, C. 
D., Shieh, W. J., Guarner, J., Paddock, C. D., Rota, P., Fields, B., DeRisi, J., ... SARS Working Group (2003). A novel coronavirus associated with severe acute respiratory syndrome. The New England journal of medicine, 348(20), 1953-1966. https://doi.org/10.1056/NEJMoa030781

Morawska, L., \& Milton, D. K. (2020). It is time to address airborne transmission of coronavirus disease 2019 (COVID-19). Clinical infectious diseases: an official publication of the Infectious Diseases Society of America, 71(9), 2311-2313. https://doi.org/10.1093/cid/ciaa939

Morawska, L., Tang, J. W., Bahnfleth, W., Bluyssen, P. M., Boerstra, A., Buonanno, G., Cao, J., Dancer, S., Floto, A., Franchimon, F., Haworth, C., Hogeling, J., Isaxon, C., Jimenez, J. L., Kurnitski, J., Li, Y., Loomans, M., Marks, G., Marr, L. C., Mazzarella, L., ... Yao, M. (2020). How can airborne transmission of COVID-19 indoors be $\begin{array}{llll}\text { minimised?. } & \text { Environment } & \text { international, } & 142,\end{array}$ https://doi.org/10.1016/j.envint.2020.105832

Pelizza, S.A., Cabello, M.N., \& Lange, C.E. (2010). Nuevos registros de hongos entomopatógenos en acridios (Orthoptera: Acridoidea) de la República Argentina. Revista de la Sociedad Entomológica Argentina, 69(3-4),287-291. https://www.redalyc.org/articulo.oa?id=3220/322028487004

Salmon, J.F. (2020). Retinal detachment. En: Salmon JF. Kanski`s Clinical ophthalmology (Eds). 9th Edición. Philadelphia, USA, Elsevier. 